University of Wollongong

Research Online

Vice-Chancellor's Unit

1994

\title{
Appropriacy judgements and pragmatic performance
}

Eeva K. Leinonen

University of Wollongong, leinonen@uow.edu.au

Benita R. Smith

Follow this and additional works at: https://ro.uow.edu.au/vc

\section{Recommended Citation}

Leinonen, Eeva K. and Smith, Benita R., "Appropriacy judgements and pragmatic performance" (1994).

Vice-Chancellor's Unit. 56.

https://ro.uow.edu.au/vc/56

Research Online is the open access institutional repository for the University of Wollongong. For further information contact the UOW Library: research-pubs@uow.edu.au 


\title{
Appropriacy judgements and pragmatic performance
}

\begin{abstract}
This paper examines judgements of inappropriacy made by groups of independent raters from different professional backgrounds when presented with data from two boys with semantic, pragmatic and syntactic difficulties, who are interacting with adults, and when presented with data in a transcript or video format. The purpose is to explore the nature of such judgements with the view to highlighting the centrality and the complex nature of inappropriacy judgements in the clinical management of pragmatic impairment. The current study suggests that consensus of view as to what is or is not appropriate in interactions involving child clients may not exist in the general population. It further suggests that professional experience with children may direct one's attention primarily to the child client. Video presentation of information also appeared to direct attention to the child interactant. Given that audiovisual presentation of data is able to reproduce the non-linguistic 'oddness' of a child (e.g. averted gaze, slumped posture, monotonous voice), a situation seems to be created in which the linguistic content is perceived as equally 'odd' or inappropriate. This study has implications for assessment, diagnosis and treatment of pragmatic difficulties in children.
\end{abstract}

\section{Keywords}

appropriacy, judgements, pragmatic, performance

\section{Publication Details}

Leinonen, E. K. \& Smith, B. R. (1994). Appropriacy judgements and pragmatic performance. European Journal of Disorders of Communication, 29 (1), 77-84. 


\title{
Appropriacy judgements and pragmatic performance
}

\author{
Eeva Leinonen \\ Department of Linguistics, University of Hertfordshire, $U K$ \\ Benita Rae Smith \\ Department of Human Communication, De Montfort University, Leicester, UK
}

\begin{abstract}
S
This paper examines judgements of inappropriacy made by groups of independent raters from different professional backgrounds when presented with data from two boys with semantic, pragmatic and syntactic difficulties, who are interacting with adults, and when presented with data in a transcript or video format. The purpose is to explore the nature of such judgements with the view to highlighting the centrality and the complex nature of inappropriacy judgements in the clinical management of pragmatic impairment. The current study suggests that consensus of view as to what is or is not appropriate in interactions involving child clients may not exist in the general population. It further suggests that professional experience with children may direct one's attention primarily to the child client. Video presentation of information also appeared to direct attention to the child interactant. Given that audiovisual presentation of data is able to reproduce the non-linguistic 'oddness' of a child (e.g. averted gaze, slumped posture, monotonous voice), a situation seems to be created in which the linguistic content is perceived as equally 'odd' or inappropriate. This study has implications for assessment, diagnosis and treatment of pragmatic difficulties in children.
\end{abstract}

Cette communication examine des jugements d'inadéquation établis par des groupes d'assesseurs indépendants lorsqu'on leur a présenté des corpus provenant de deux garçons souffrant de difficultés sémantiques, pragmatiques et syntactiques, en train de s'entretenir avec des adultes. Les corpus étaient soit sous forme de transcriptions, soit des enregistrements de vidéos. Le but de la recherche est d'examiner la nature de jugements de ce genre, afin de mettre l'accent sur l'aspect central et complexe des jugements d'inadéquation lors du traitement de la déficience pragmatique. L'étude en cours suggère qu'il y a des chances qu'au sein de la population en général on ne trouve pas l'unanimité à propos de ce qui est adéquat et inversement lors d'interactions avec une clientèle d'enfants. Ceci implique en outre qu'une expérience professionelle de contacts avec des enfants peut aider à se concentrer avant tout sur l'enfant. La présentation du corpus sous forme d'enregistrement vidéo semble aussi diriger l'attention sur l'enfant. Etant donné que la présentation audio-visuelle permet de reproduire les 'bizarrerries' extra-linguistiques de l'enfant (par ex. le regard qui se détourne, une posture affaissée, une voix monotone), on crée une situation où le contenu linguistique est perçu comme également 'bizarre' ou inadéquat. Cette étude peut se révéler utile pour l'évaluation, le diagnostic et le traitement des difficultés pragmatiques chez l'enfant.

Dieser Aufsatz untersucht die Unangemessenheitsurteile von unabhängigen Beurteilergruppen, die Daten über zwei Jungen mit semantischen, pragmatischen und syntaktischen Schwierigkeiten bei ihrer Interaktion mit Erwachsenen sowie Daten als Transkript und in Videoformat erhalten. Ziel der Untersuchung ist die Durchleuchtung solcher Urteile, um die zentrale Stellung und die Komplexität von Unangemessenheitsurteilen bei der Behandlung pragmatischer Störungen zu unterstreichen. Diese Studie konstatiert, daß ein Konsens über das, was bei Interaktionen mit 
Kindern als angemessen gilt, wahrscheinlich bei der normalen Öffentlichkeit nlcht existiert. Weiter ist anzunehmen, daß berufliche Erfahrung mit Kindern die Aufmerksamkeit primär auf das Kind lenkt. Die Videoprïsentation von Information schien die Aufmerksamkelt ebenfalls auf das Kind zu lenken. Dadurch daß eine audio-visuelle Darbietung die nicht-linguistische 'Seltsamkeit' eines Kindes (z.B. den abgewendeten Blick, die zusammengesunkene Haltung, die monotone Stimme) wiedergeben kann, scheint eine Situation geschaffen $z u$ werden, in der linguistische Inhalt gleichermaßen 'seltsam' oder unangemessen erscheint. Diese Studie hat Implikationen fïr die Lvaluierung, die Diagnose und die Behandlung von pragmatischen Problemen bei Kindern.

Key words: (in)appropriacy judgements, pragmatic impairment.

\section{INTRODUCTION}

As a result of the growing clinical awareness of pragmatic difficulties, the perceived appropriacy of client's communicative behaviours has come to be regarded as valuable diagnostic information. However, when making judgements of appropriacy, it is easy to assume a consensus view as to what behaviour is and is not appropriate for clients, particularly child clients. Such a consensus might or might not exist in the general population and is likely to be influenced by cultural and subcultural factors. What might be perceived as politeness in one culture might be interpreted by members of another culture as evasiveness. Similarly, a teacher might come to regard passively responding behaviour on the part of pupils as generally desirable. In the speech and language pathology context, therapists may assume normality in the type of interaction favoured by, or encouraged, by themselves, whereas non-members of the profession might regard this type of interaction as stilted or in some way unusual. Also, behaviours such as child initiations, which may occur rarely in the clinical or classroom situation, could, in the absence of normative data, be assumed to occur rarely in all situations.

When making appropriacy judgements in professional contexts, it is helpful to bear in mind not only the potential lack of consensus but also that the client's behaviour might be a consequence of the interactive situation rather than of disability. Attention has been drawn to the effect of interactive partners upon one another in the construction of discourse (Levinson, 1983; McTear, 1985). There is the possibility that the contributions of either partner may be responsible for inappropriate contributions on the part of the other participant. The importance of sampling behaviour in a variety of contexts has also been stressed (Gallagher, 1983; McTear, 1985). Further difficulties may arise in unequal encounters such as those between an adult and a child (Smith \& Leinonen, 1992).

Even when the considerations above have been taken into account, behaviour that is accurately judged to be inappropriate may not provide reliable diagnosis of pragmatic disability, because the behaviour may result from other factors such as anxiety, defensiveness or use of compensatory strategies (McTear \& Conti-Ramsden, 1992; Smith \& Leinonen, 1992). Surface behaviour may not therefore be a true indicator of underlying ability.

Because of the centrality and complexity of appropriacy judgements, it is essential to know more about them. Appropriacy judgements have been part of pragmatic assessment from the outset. In Prutting and Kirchner's (1983) 
'Pragmatic Protocol', observers are asked to decide whether certain communicative behaviours are 'penalizing to the client' (p. 44) and are therefore to be recorded as inappropriate. In McTear's (1985) preliminary checklist of discourse skills, judgements of appropriacy are made in relation to responses. The nature of these judgements was not focused on at the time when these checklists were constructed. A further complication arises from McTear and Conti-Ramsden's (1992) observation that utterances may be simultaneously appropriate on one pragmatic dimension and inappropriate on another, in which case one would need to know which dimension should be focused upon or given precedence.

In a study that identified conversational features leading to judgements of inappropriacy, Bishop and Adams (1989) aimed to facilitate the recognition of children for whom conversation presents problems and to provide a basis for detailed investigation of specific areas of communicative difficulty. Agreement was found between three raters: the two authors and a person who was specifically trained to identify certain features of behaviour as inappropriate. Acknowledging that Bishop and Adams consider this study as 'a necessary first step towards devising more rigorous and objective criteria for classification' (Adams \& Bishop, 1989, p. 213), there remains the question as to whether the circularity involved in training professionals to regard certain features of behaviour as inappropriate should discourage the definition of such features as symptomatic of a disorder. Inadequate examination of the issues involved before the identification of the features might render their wholesale adoption as diagnostic criteria premature.

It may be somewhat premature to focus clinical attention on predetermined categories when relatively little is known about the nature of disordered pragmatic functioning. An approach that does not constrain observations is more likely to lead to further understanding. Assessment categories also tend to focus exclusively on the child's contribution to inappropriacy in discourse, thus directing attention away from the possibility that other interactants' behaviour may contribute to the perceived inappropriacy of the child's behaviour (Smith \& Leinonen, 1992).

Perhaps the greatest reservation in connection with using inappropriacy categories in diagnosis stems from lack of normative data on what constitutes appropriate pragmatic behaviour. There may well be developmental stages at which certain of the features identified as inappropriate (e.g. constant questioning or excessive initiation) are normal. This problem is identified by Bishop and Adams (1989). In the absence of normative data there is a danger that professionals might come to regard the features themselves as undesirable in much the same way that grammatical 'errors' were frowned upon before the developmental validity of child grammar was understood.

Given that more needs to be known about inappropriacy judgements, an investigation was conducted to examine whether individuals from different professional backgrounds, who had been given no specific training, would make similar or different inappropriacy judgements. It was also examined whether judgments differed according to whether the interactions were presented in transcript or video format. 


\section{SUBJECTS}

Eighteen adults participated in study 1. Eight of the adults had varying professional backgrounds (e.g. an artist, a housewife, a senior manager, a secretary) and ten were second year teacher trainee students majoring in language and communication. These constitute groups 1 and 2 respectively.

Twenty adults with varying professional backgrounds (e.g. a retired gas worker, a librarian, a secretary) participated in study 2 , ten in each experimental condition: video-recording versus transcript. These are referred to as groups 3 and 4 respectively.

\section{METHOD}

In study 1 the subjects were given a transcript of a conversation between a 7-year-old boy with semantic, pragmatic and syntactic difficulties and two adults (a speech and language therapy student and a linguist). The subjects were asked to mark anything that struck them as odd or inappropriate in either the adults' or the child's contributions on the written transcript. The subjects were urged not to deliberate over judgements but to proceed fairly quickly. No training or additional information was given. The instructions were given in both spoken and written form.

In study 2 ten subjects were shown a video-recording of a conversation between a 10 -year-old boy with semantic, pragmatic and syntactic difficulties and two adults (a speech and language therapist and a technician). The subjects were asked to stop the video tape at any point where they thought the utterances or communicative behaviours of either the adult or the child were in any way odd or inappropriate, and to mark these on a written transcript of the video-recorded conversation. Again, the subjects were asked not to deliberate over judgements and were given no adiditional training or information. The other ten subjects in study 2 were given a written transcript of the viceo recording and were asked to make appropriacy judgements on the basis of this alone. Thus, the video group was in possession of information regarding non-verbal and paralinguistic features of the interaction, whereas the transcript group was not.

\section{RESULTS}

Overall, only around $10 \%$ of interactive contributions were deemed in some way inappropriate by the raters. Despite the linguistic and pragmatic difficulties of the two boys involved, an overall impression of working interactions was created.

The percentage of utterances judged inappropriate by the four groups of observers and the percentage of different utterances which were judged as being inappropriate (i.e. variability in judgements) are summarised in Tables 1 and 2. Table 1 shows the extent to which the subjects in the four groups judged contributions as inappropriate, whereas Table 2 shows the extent to which the subjects judged different (or, conversely, same) contributions as inappropriate. No significant differences were found in the total number of inappropriacy judgements by the different raters or in different presentation 
Table 1: Percentage of utterances judged inappropriate.

\begin{tabular}{lccccc}
\hline & \multicolumn{2}{c}{ Study 1 } & & \multicolumn{2}{c}{ Study 2 } \\
\cline { 2 - 3 } \cline { 5 - 6 } & Group 1 & Group 2 & & Gronp 3 & Group 4 \\
\hline Total & 9.98 & 11.93 & 9.59 & 10.26 \\
Child & 57.96 & 94.67 & 92.79 & 61.41 \\
Adult & 42.04 & 5.33 & & 7.21 & 38.60 \\
\hline
\end{tabular}

Total: percentage of utterances judged inappropriate as a function of the total number of utterances. Child: percentage of child utterances judged inappropriate as a function of the total number of inappropriate utterances.

Adult: percentage of adult utterances judged inappropriate as a function of the total number of inappropriate utterances.

Table 2: Percentage of different utterances judged inappropriate.

\begin{tabular}{llllll} 
& \multicolumn{2}{l}{ Study 1 } & & \multicolumn{2}{l}{ Study 2 } \\
\cline { 2 - 3 } \cline { 5 - 6 } & Group 1 & Group 2 & & Group 3 & Group 4 \\
\hline Total & 51.77 & 31.36 & & 31.25 & 39.15 \\
Child & 40.46 & 28.75 & & 28.50 & 52.87 \\
Adult & 67.38 & 77.78 & & 66.67 & 31.08 \\
\hline
\end{tabular}

Total: percentage of different utterances judged inappropriate as a function of the total inappropriate utterances.

Child: percentage of child utterances judged inapproriate as a function of the total different inappropriate utterances.

Adult: percentage of adult utterances judged inappropriate as a function of the total different inappropriate utterances.

methods. Individuals were, however, found to focus differently on adult and child contributions.

In study 1 child contributions were judged inappropriate more than adult contributions by group 2 (Wilcoxon Signed-Ranks Test; $p<0.01$ ). Group 1 found both adults and children contributing more equally to inappropriacy in discourse. An across group comparison shows that group 2 judged child contributions inappropriate more than group 1, and, conversely, group 1 judged adult contributions inappropriate more than group 2 (Mann-Whitney Test; $p<0.05$ ).

Raters in group 2 agreed less when judging adult contributions than when judging child contributions (Wilcoxon Signed-Ranks Test; $p<0.02$ ). The same tendency was also evident in group 1 but not to a significant degree. An across-group comparison showed that one group did not show greater variability in judgements than the other group.

In study 2, which focused on the method of presentation, group 3 (video group) behaved very similarly to group 2 in study 1 . They focused more on the child as compared to the adult contributions (Wilcoxon Signed-Ranks Test; $p<0.01$ ). This comparison was not significant for group 4. All other comparisons in study 2 mirror the results of the comparisons in study 1 , as can be seen in Tables 1 and 2 . 


\section{DISCUSSION}

Differences in judgements of inappropriacy occurred in groups of independent raters whose professional training had or had not focused upon child language and who were presented with data in different modes (video versus transcript). The study does not attempt to explain why the differences are found but to highlight the following points:

1. Consensus of opinion does not necessarily exist among independent raters.

2. The raters in this study agreed with professional opinion that the children's contributions were in some ways odd and inappropriate.

3. Professional experience of raters appeared to affect whether judgements fell on adult or child contributions.

4. The information available in different presentation modes had an influence on the nature of inappropriacy judgements.

Study 1 points to a the tendency of a group of language-trained teacher trainees to consider child contributions as most inappropriate, attributing to the child interactant the responsibility for problematic interactions, and thus not considering the potential effects of other interactants on the child's behaviour. The professionally mixed group of raters considered the adults' style of interacting as also contributing towards problematic discourse. This observation poses the following question: Does a primary focus on child contributions militate against identification of problems in pragmatics and discourse which by definition manifest themselves in shared communication? It may be that prior knowledge of analytical categories and the nature of children's pragmatic failures might direct one's attention to the contributions that are supposed to be failing rather than to a child's successes. It is well documented that individual utterances or speech acts cannot be judged in isolation because they depend for their validity upon events elsewhere in the discourse (Levinson, 1983; McTear, 1985; Skarakis-Doyle \& Mentis, 1991). This tentative finding suggests that it is worth examining more closely how professionals make appropriacy judgements and considering the implications of this for clinical assessment, diagnosis and remediation.

The mode of presenting the data also appears to have an effect on whether one focuses on child or adult contributions. Those in the transcript group found that both adult and child utterances contributed to inappropriacy in the interaction, whereas the video group focused almost exclusively on the child even though the camera did not. What is striking is the almost identical nature of the profiles of the mixed professional video group (group 3) and the language-trained teacher trainee transcript group (group 2). Given the judgements of the two other groups (groups 1 and 4), which consist of individuals of varying professional backgrounds, one could expect the third such group (group 3) to behave similarly, but they did not. One probable explanation for this is that the audiovisual presentation of data highlights the non-linguistic 'oddness' of the child (the averted gaze, the slumped posture and the monotonous voice), thus creating a situation in which the linguistic content of child contributions may be overshadowed by these features and thus perceived as equally 'odd' or inappropriate. In the transcripts, however, focus is more on the linguistic and discourse functioning of individuals, thus bringing 
about a more balanced view of the child and the adult in the interaction. On the other hand, it could be that the transcript unreasonably portrays the adult in an unfavourable light, by removing evidence of her supportive non-verbal and paralinguistic behaviours. Whatever the interpretation, it seems that real life communicative partners are likely to react to physical and suprasegmental features of clients' behaviour. This suggests that further thought could usefully be given to the relative value of intervening in linguistic and extra-linguistic features of clients' behaviours. It also raises the questions of whether extralinguistic inappropriacy masks linguistic adequacy and whether this, in turn, leads to dismissive interactions. More widespread understanding of this possibility might well be clinically valuable.

The current study also suggests that variability in judging the child's contributions is less marked in the group whose members are professionally familiar with normal children's conversation than in the professionally mixed group. It further highlights the fact that mode of presentation affects consistency of judgements. The group that focused on transcript alone agreed less as to which of the child contributions were inappropriate as compared to the group with audiovisual information. All groups except the group focusing on a transcript of the video recording exhibited greater variability in judging adult contributions than child contributions. It is not clear why one of the groups would reach greater agreement than the other groups in this instance. However, the extent of the disagreement in these other groups might suggest that the concept of adult inappropriacy in adult-child interaction is not sufficiently familiar for consensus to have been reached.

\section{CONCLUSION}

Making judgements of (in)appropriacy is part of the speech and language clinician's professional contribution to the management of pragmatic impairment. Such judgement may contribute to the assessment and diagnosis of a disorder in a client or may influence the setting of goals for intervention. It is therefore necessary to examine carefully the nature of appropriacy judgements. To this end the present study has highlighted certain aspects of these judgements which merit further investigation. It has drawn attention to the degree of consensus achieved in certain circumstances as well as to the potential lack of consensus as to what constitutes inappropriacy in discourse. It has also drawn attention to interactants' shared responsibility for communicative success and failure to the influence of the mode of presentation of data and professional training on one's view of clients' abilities.

\section{ACKNOWLEDGMENT}

We would like to thank Celia Piggins for collecting data for the video group.

\section{REFERENCES}

ADAMS, C. \& BISHOP, D. V. M. (1989). Conversational characteristics of children with semantic-pragmatic disorder I: Exchange structure, turntaking, repairs and cohesion. British Journal of Disorders of Communication 24, 211-239. 
BISHOP. D. V. M. \& ADAMS, C. (1989): Conversational characteristics of children with semantic-pragmatic disorders II: What features lead to judgements of inappropriacy? British Journal of Disorders of Communication 24, 241-63.

GAIIAGHER, T. M. (1983). Pre-assessment: a procedure for accommodating language use variability. In T. M. Gallagher \& C. A. Prutting (Eds), Pragmatic Assessment and Intervention Issues in Language. San Diego, CA: College-Hill Press.

LEVINSON, S. C. (1983. Pragmatics. Cambridge: Cambridge University Press

MCTEAk, M. (1985). Children's Conversation. Oxford: Blackwell.

metFaf, M. \& CONTI-RAMSDen, G. (1992). Pragmatic Disability in Children. London: Whurr.

PRUTTING, C. A. \& KIRCHNkR, D. M. (1983). Applied pragmatics. In T. M. Gallagher \& C. Prutting (Eds), Pragmatic Assessment and Intervention Issues in Language. San Diego, CA: College-Hill Press.

SKARAK.IS-DOYLE, E. \& MENTIS, M. (1991). A discourse approach to language disorders: Investigating complex sentence production. In T. M. Gallagher (Ed.), Pragmatics of Language: Clinical Practice Issues. London: Chapman \& Hall.

SMITH, B. R. \& LEINONFN, F. (1992). Clinical Pragmatics: Unravelling the Complexities of Communicative Failure. London: Chapman \& Hall.

Address correspondence to Dr Eeva Leinonen, Department of Linguistics School of Humanities and Education, University of Hertfordshire, Wall Hall Campus, Aldenham, Watford, Herts WD2 8AT, UK.

Received March 1993; revised version received July 1993. 